\title{
RADICAL AND RATIONAL MEANS OF DEGREE TWO
}

\author{
MOWAFFAQ HAJJA
}

Abstract. In this paper, we introduce two families of means that encompass many of the classical means and we characterize the internality properties in these families. We determine the comparability relations within these two families and we study their behavior under equal increments of the variables. We also introduce a geometrical context that gives rise to one of these families.

Mathematics subject classification (2000): 26D05.

Key words and phrases: Quadratic forms, quadratic radical mean, quadratic rational mean, internality.

\section{REFERENCES}

[1] J. ACZÉL AND ZS. PÁLES, The behaviour of means under equal increments of their variables, Amer. Math. Monthly 95 (1988), 856-860.

[2] J. ACZÉL, S. LOSONCZI AND Zs. PÁLES, The behaviour of comprehensive classes of means under equal increments of their variables, Numerical Mathematics 80 (1987), 459-461.

[3] P. J VAN AlBADA, Geometric inequalities and their geometry, Univ. Beograd. Publ. Elektrotehn. Fak. Ser. Mat. Fiz. No. 338-352 (1971), 41-45.

[4] E. F. BeCKenBach, A class of mean value functions, Amer. Math. Monthly 57 (1950), 1-6.

[5] M. BERGER, Geometry I, Springer-Verlag, Berlin, 1987.

[6] J. M. Borwein AND P. B. Borwein, The way of all means, Amer. Math. Monthly 94 (1987), 519-522.

[7] O. Bottema and J. T. Groenman, On some triangle inequalities, Univ. Beograd. Publ. Elektrotehn. Fak. Ser. Mat. Fiz. No. 577-598 (1977), 11-20.

[8] J. L. BRENNER AND M. E. MAYS, Some reproducing identities for families of mean values, Aequationes Math. 33 (1987), 106-113.

[9] P. S. Bullen, Averages still on the move, Math. Mag. 63 (1990), 250-255.

[10] P. S. Bullen, D. S. Mitrinović And P. M. VAsić, Means and Their Inequalities, D. Reidel Publishing Company, Dordecht, Holland, 1988.

[11] M. D. ChoI, T. Y. LAM AND B. REZnICK, Even symmetric sextics, Math. Z. 195 (1987), 559-580.

[12] M. D. Chol, T. Y. LAM AND B. ReZnick, Positive sextics and Schur's inequalities, J. Algebra 141 (1991), 36-77.

[13] E. L. DoDD, The substitutive mean and certain subclasses of this general mean, Ann. Math. Stat. 11 (1940), 163-176.

[14] H. EvES, An Introduction to the History of Mathematics, 5th edition, Saunders, Philadelphia, 1983.

[15] H. EvES, Great Moments in Mathematics (before 1650), Doliciani Math. Exp., No. 5, MAA, Washington, D.C., 1980 .

[16] D. FARnsworth And R. ORR, Gini means, Amer. Math. Monthly 93 (1986), 603-607.

[17] D. FARNSWORTH AND R. ORR, Transformation of power means and a new class of means, J. Math. Anal. Appl. 129 (1988), 394-400.

[18] R. J. GREgORAC, A law of cosines in $\mathbb{R}^{n}$, Nieuw Arch. Wisk. 3 (1991), 267-269.

[19] M. HAJJA, Internal cubic forms in three variables, preprint.

[20] M. Hall and M. Newman, Copositive and completely positive quadratic forms, Proc. Camb. Phil. Soc. 59 (1963), 329-339.

[21] L. Hoehn And I. Niven, Averages on the move, Math. Mag. 58 (1985), 151-156.

[22] M. S. KLAMKIN, On some symmetric sets of unit vectors, Math. Mag. 64 (1991), 271-273.

[23] A. Prestel AND C. N. Delzell, Positive Polynomials, Springer, New York, 2001. 
[24] RaJwade, Squares, London Math. Soc. Lecture Note Ser. 171, Cambridge Univ. Press, 1993.

[25] J. F. RIGBY, A method of obtaining related triangle inequalities, with applications, Univ. Beograd. Publ. Elektrotehn. Fak. Ser. Mat. Fiz. No. 412-460 (1973), 217-226.

[26] J. F. RigBY, Sextic inequalities for the sides of a triangle, Univ. Beograd. Publ. Elektrotehn. Fak. Ser. Mat. Fiz. No. 498-541 (1975), 51-58.

[27] J. F. RigBY, Quartic and sextic inequalities for the sides of triangles, and best possible inequalities, Univ. Beograd. Publ. Elektrotehn. Fak. Ser. Mat. Fiz. No. 602-633 (1978), 195-202.

[28] G. TOADER, Integral generalized means, Math. Inequal. Appl. 5 (2002), 511-516.

[29] S. TOADER, Derivatives of generalized means, Math. Inequal. Appl. 5 (2002), 517-523.

[30] M. K. VAMANAmurthy AND M. VuORINEN, Inequalities for means, J. Math. Anal. Appl. 183 (1994), $155-166$. 